\title{
The Space Between: Exploring the Interplay of Mediation and Applied Theatre Practices to Create Space for Dialogue and Support
}

\section{Nadia Siddiqui, Michelle O'Connor-Hill, Brisa Muñoz, and Lili Nikolova}

\begin{abstract}
This paper seeks to explore the intersection of mediation and artistic and embodied practices used in peacebuilding contexts, particularly applied theatre, by describing the theoretical underpinnings of both and examining their combined practical application. We will do this in part by examining findings from a workshop utilizing applied theatre techniques to engage mediators in discussion on 1) systems of professional support and 2) combining more artistic and embodied approaches to their own work. Overall workshop findings indicate that mediators are receptive and interested in using more embodied and non-verbal approaches within their practice.
\end{abstract}

\section{Keywords}

Mediation, interplay, theatre practices, dialogue, support

Mediation is a practice that requires, among other skills, creativity and nuance to facilitate. The overarching aim of mediation, to create safe space for stakeholders to advocate for their needs and develop strategies to end disputes without violence, dovetails with a number of artistic practices, including applied theatre. Applied theatre refers to the practice of theatre and drama in non-traditional settings and/or with marginalized communities. It encompasses theatre practices, including participatory theatre and storytelling methodologies, which tackle areas of social justice and cultural policy with an aim of helping communities identify solutions to social problems. Like mediation, it is underpinned by the values of self- determination, confidentiality, impartiality, safety, and quality. In this way, it could be said that applied theatre techniques can serve as a physical embodiment of mediation. Despite this link, there is a 
dearth of research on the embodied and physical aspects of mediation as a practice and the potentials of using more non- verbal approaches to disputed topics. More to the point, while mediation is seen as a kind of art form and actual arts-based approaches have similar goals as mediation, there is little in the way of research exploring the two and their intersection in practice.

This paper then seeks to address these gaps by describing the theoretical underpinnings of mediation and applied theatre and exploring their combined practical application, including uses of nonverbal interaction. We will do this by describing and examining findings from a workshop the Applied Theatre Collective (ATC) facilitated at the Seventh Annual International Mediators Beyond Borders Congress, utilizing applied theatre techniques to engage mediators in discussion on systems of professional support and combining more artistic and embodied approaches to their own work.

\section{Mediation and Applied Theatre}

While the process of mediation is open to interpretation, in general it involves a neutral third party working with those in conflict to help them change the quality of their conflict interaction from negative and destructive to positive and constructive as they discuss and explore issues and possibilities for resolution (Bush \& Folger, 2005). As such, mediation seeks to be transformative, facilitative, and directive to allow parties to access new information, encourage needed change, and develop new options for problem-solving (New York Peace Institute, 2013). It is through these principles and actions that mediation connects with applied theatre, particularly participatory theatre and storytelling methodologies. Performative arts and storytelling in conflict and transitional settings can provide a bridge to positive and constructive interaction by engaging with the "moral imagination," the capacity for individuals to stay grounded in the troubles of the real world, while simultaneously remaining open to the possibilities of a better one (Cohen et al., 2011:11).

Theatre and storytelling in particular then can play a role in giving voice to the marginalized and in demanding the right to speak publicly without fear (Neelands, 2009: 180). These forms encourage present and forward looking understanding by making relationships central and acknowledging interdependence among people and societies; cultivating paradoxical curiosity through inquiry about identities, values, and beliefs leading to understanding that is above simple dualities; making space for the creative act in contexts where political violence would make it seem that there are no options for cultural action and response; and finally, enabling risk-taking to allow people to examine possibilities of what a peaceful society could look like (Cohen et al, 2011: 11-12). In short, these practices help in addressing the outer social world, the inner psychological world, and the transitional zone between the two within individuals and communities, which are crucial elements to post-conflict reconstruction.

Having people actively participate in the transformation process is a central principle not only of peacebuilding but of community-based theatre as well. It offers participants an aesthetic instrument to analyse their past in the context of the present, and to invent and shape their futures according to their needs, determined through participatory theatre exercises and games, without having solutions imposed on them by experts (UNAMA, 2008). The underlying assumption is that people are all equipped to be 
actors and to take center stage. The main theatrical focus is on dialogue, with the explicit aim of allowing participants to take control of situations rather than simply having things happen to them.

Community-based theatre is most closely identified with Brazilian theatre director Augusto Boal and his Theatre of the Oppressed, which became an international movement using his techniques as vehicles for participatory social change in the mid- twentieth century (Singhal, 2004). For Boal, many ordinary citizens feel powerless and are in fact blocked in the face of oppression and injustice. To address this, he developed the Theatre of the Oppressed process whereby audience members, so- called spectactors, can stop a performance and assume a protagonist role onstage to change the dramatic action, propose various solutions, discuss plans for change, and train themselves for social action (UNAMA, 2008). The theatrical act itself becomes a conscious intervention and a rehearsal for social action, based on collective analysis (Singhal, 2004: 146).

Among the components of Boal's approach are 1) Image Theatre, a basis for other participatory theatre work that asks participants to transform their own or others' bodies into representations of particular situations, emotions, or ideas; and 2) Forum Theatre, which allows audience members to stop a scene or play showing a conflict that the characters do not know how to resolve/transform and suggest and try out possible solutions. "Joker" characters serve as neutral moderators between the actors and the spect-actors, setting up the rules of the event for the audience, facilitating the spect-actors' replacement of the protagonist on stage, and summing up the essence of each proposed solution in the intervention. The term itself derives from the joker or wild card in a deck of playing cards, where that card is not tied to a specific suit or value, neither is the Theatre of the Oppressed joker tied to an allegiance to any one performer, spect-actor, or interpretation of events (Singhal, 2004: 148).

Storytelling methodologies and exercises also require a neutral moderator and can be used in tandem with Theatre of the Oppressed approaches or on their own. One of the most prominent techniques is the story circle in which participants sit, unencumbered in a circle and within a specific period of time each tells a personal story around a given theme. The role of the other participants is to listen intently and deeply to what is being said. Once each individual has shared his/her narrative, participants can engage in cross-talk or dialogue about what they have just heard to ask clarifying questions or generate themes connecting these experiences (Research Center for Leadership Action, 2008: 2). The importance of these techniques lies in the way in which they empower individuals as "personal stories position even the least powerful individual in the subject position, the I, since everyone is an expert on his or her own life" (Cohen-Cruz, 2005: 139). At the same time, they allow participants to identify and explore patterns relating to an experience, problem, or issue and find common threads of experience, building deeper relationships by illuminating these connections (Research Center for Leadership Action, 2008:1).

Taken together participatory theatre and storytelling exercises help develop creative space "in which people feel safe enough to take risks and to allow themselves and others to experience vulnerability" (Nicholson, 2005: 129). This space and these processes can present stories about specific communities or groups, laying the groundwork for bonding and interactivity within the community 
(Bharucha, 2001: 3767). This is important in bringing divided communities together and in helping to activate what William Ury (1999: 7) terms the "third side," the surrounding community within a conflict, which can serve as a container for escalating violence. Without it, "serious conflict . . all too easily turns into destructive strife. Within the container, however, conflict can gradually be transformed from confrontation into cooperation" (Ury, 1999: 7).

\section{Mediation as an Embodied Practice}

It is the way arts practices used within conflict resolution and peacebuilding contexts can help promote empathy, moral development, connectedness, social agency, and critical thinking - all necessary tools for containing violence and ending disputes - that connect them to mediation settings in these environments. At the same time, theatre in particular as an art form functions as a vital act of transfer, transmitting social knowledge, memory, and a sense of identity through reiterated behaviours (Taylor, 2003: 2). This emphasis on behaviours is also critical in mediation, even if the more embodied and physical aspects of it can be obscured by the terms used to describe the process, including "dialogue and negotiation" (Nathan, 2010:1).

On the surface this seems to indicate purely verbal communication. However, the terms instead serve to describe "the constellation of acts and communications that extend beyond any particular negotiation and encompasses every manner of expression or action, whether formal or informal, that serves to manage, minimize, or settle issues or differences that arise between people" (Benjamin, 2012, 1). This acknowledgement of the wide-ranging nature of acts and communications throughout mediation also indicates that the body itself changes while attempting to move from conflict to resolution. Awareness of the body and its responses is a cornerstone to the treatment of trauma and post-traumatic stress disorder (PTSD) because such awareness makes it possible to gauge, slow down, and halt traumatic hyper arousal, and to separate past from present (Rothschild, 2000: 100). Bodies and minds in conflict function in a similar fashion and having the ability to be aware of body sensations, facial expressions, and posture keeps individuals from getting lost in past grievous experiences and focused on the present while presenting them with very real, physical manifestations of change (Rothschild, 2000: 107). What does the body look and feel like when in conflict? When at ease? How is the body changing throughout the process of mediation? And what do these changes in sensation and behaviour mean within the context where conflict and dispute are taking place? Stripped of the language and rhetoric of difference and division, bodies in motion have the power to captivate and connect, engrained as they are with centuries of meaning in particular contexts that people in those contexts intrinsically understand (Cohen, 2005: 72). In this way, incorporating more specifically non-verbal, physical, and performative acts within a mediation process may allow people to feel without being re-traumatized and gain deeper insight into the issue at hand, allowing others who have perhaps a different experience to see the issue from another perspective in a manner that is not antagonistic, but rather as a problem to solvetogether.

It was with these questions and this understanding of the uses of applied theatre techniques for community problem-solving that the ATC, a small not-for-profit organization formed by applied theatre 
practitioners and peacebuilding specialists dedicated to promoting dialogue through the arts, sought to design an interactive workshop for an international group of mediators at the Seventh Annual International Mediators Beyond Borders Congress exploring the uses of theatre methodology within mediation practice and as a means of creating spaces for professional support to those who negotiate the resolution of conflict in often violent settings.

\section{Applied Theatre Workshop}

The Mediators Beyond Borders Congress brought together over 200 mediators from around the world, from those working with youth in public schools in Los Angeles to those working to broker peace between the Philippine government and armed groups to those at the front lines of trying to quell sectarian violence in Kenya and Indonesia. In seeking to develop a workshop for the 2015 proceedings, whose theme centered on "Dangerous Dialogues and Courageous Conversations: Peacebuilding in the $21^{\text {st }}$ Century," ATC wanted to examine the ways in which mediators balance their own personal views with the professional expectations of their role in conflict resolution and peacebuilding and to introduce applied theatre techniques as possible tools for use in these contexts where impartiality and neutrality are both seemingly required and also difficult to maintain.

To the first point, we wanted to pay heed to what mediators felt were their needs for professional support given the complexity, stress, and oftentimes danger involved in their jobs, particularly in postconflict settings. The common response around support for mediators comes in giving them more technical skills, from greater mediation expertise, country and regional expertise, thematic expertise, communications expertise, and management expertise (Nathan, 2010: 2). This however does not take into account the very real physical and emotional toll these unchecked stressors can have on an individual, including professional burnout and vicarious trauma, which entails emotional exhaustion or depletion of emotional resources; detachment from the job and the people being served; and a reduced sense of personal accomplishment (Maslach et al., 2001: 403). To the second, we wanted to engage participants with applied theatre methodologies around this theme of support and also open up discussion on how these types of more embodied techniques could help in fostering greater trust among parties to resolve conflicts and disputes in a neutral and safe way.

In designing the 90-minute workshop session entitled "Creative Approaches for Support: ArtsBased Dialogue for Building Professional Support Amongst Mediators," with these two aims in mind, we began by seeking to engage participants in a non- verbal activity to ensure people did not feel overwhelmed initially by theatre-making and not feel pressured to talk immediately. This activity focused on building relationships in small groups, using their bodies to form geometrical shapes. From here we moved participants into a process of making images with their bodies related to the core values of mediation. The rationale for this was to have participants embody these norms to establish that they are in fact norms and mediators across settings have a universal language from which to start. This nonverbal examination of seemingly common language offered a way for participants to think about concepts they all know but in a different way. The group started thinking about how making an image allows 
individuals to see concepts and issues that are perhaps taken for granted in a new light, uncovering possible tensions, contradictions, or opportunities within these values and mediation.

Once these ideas were established in the room, we then asked participants how they balance their personal views of the world with the professional values and responsibilities of mediation. Again, this activity centred around image-making as a way to build on a skill participant just learned and was a safe way to start broaching the topic of internal conflict within their own work. This then transitioned into more intimate pair-work, where participants were asked to share with one another how and why they became mediators in the first place. Partners were to take turns listening to these stories and providing one another with a poem or three-sentence narration of what they heard. The intention here was to establish a new way of being heard - not simply to say, "I hear you," but to listen and offer a gift of another person's story back to them. In building this trust amongst participants, we were able to set up space for the next activity, a reflection walls where participants were asked to briefly write out challenges they faced in their work as mediators. In writing down and reflecting on what others had written, participants prepared for brainstorming around what an ideal image of mediation work would look like and how to get there based on the challenges identified.

This led into the final exercise of the workshop, a Boalian technique called image of transition where one participant volunteered to create a physical image of where she currently saw herself as a mediator, then offered an image of where she wanted to be, after which the group worked together to physically identify the steps it would take to get her to her ideal image. Throughout the workshop, participants were encouraged to reflect and discuss each exercise and their thoughts as to why they were or were not useful. The workshop ended with a final reflection on the role of mediators in society and the ways in which more embodied approaches may help in meeting both internal challenges mediators face as well as improving their ability to help resolve conflicts in their communities.

\section{Mediators' Response}

A theme that emerged throughout the proceedings was that of the risks faced by mediators in these contexts, from threats of physical harm to vicarious psychosocial trauma, and the ways in which to grapple with them. This made ATC's workshop topic and methodology timely and well placed for these proceedings. And as such, we had in total 20 workshop participants who were either mediators themselves or had some connection to peacebuilding and worked in a wide range of contexts.

As we moved from introductions to non-verbal representation to deeper listening and reflection exercises, it was clear that participants were building bonds and a sense of camaraderie - they shed tears, laughed, exchanged contacts, and generally felt safe with each other, even for that short time. A number of participants affirmed these sentiments and behaviors during the workshop:

"It doesn't take long to create a bond. The potential to bond more and more people."

"It was very interactive experience and nice to meet people and to see what I am good at and what I'm afraid of. And seeing that there are people like me." 
"I felt the space was safe and I've got lots of things to think about."

The pair-activity, where participants had to share their reasons for becoming a mediator and have their partner tell their story back was particularly resonant with this group in terms of building trust and connection:

"You feel seen which is a nice thing, feeling invisible is hard and recognition is really significant."

"Acknowledged and honored. Like a gift given."

From this point of acknowledgment, participants seemed willing and able to highlight the challenges they face as mediators, particularly around neutrality and/or impartiality that pose threats to themselves and their work:

"For me biggest challenge is being impartial. Also an assumption built in; but if doesn't resonate, don't have to answer."

"When connecting with human beings, hard to shut down after the process so you take home emotions and sometimes it is difficult to be professional when it comes to that. It is easier as an attorney because you have a side, but as a mediator, you don't have one and can connect as people on deeper level."

"The issue of neutrality - It makes me think is that even possible or do you have to take a position of partiality?”

"Don't judge, not easy and don't suffer for the victims."

"It's unrealistic to think can be totally impartial because we have histories but can recognize that and hold that bias and have that not impact ... is hard to do, but need to try."

Furthermore, as one participant noted in acting out her and her colleagues' challenges in mediating violent sectarian conflicts at the community level, "We feel threatened, and need to protect ourselves, but don't want to move away from vision of creating a tolerant society." In instructing others on the ways in which to physically move from a state of insecurity and vulnerability to one of confidence and harmony, she was able to identify the cycles of strife, courage, risk taking, release, and perseverance inherent in this process.

The overall consensus from participants during the final reflection session of the workshop was how useful and intriguing they found the participatory theatre and storytelling methodologies as a way to start broaching difficult topics within their own mediation work:

"I find it inspiring. I work in a local setting and knowing that there are a lot of ways of speaking of conflict and want to learn more about the methods. Wish more time to learn."

"Useful in my work with minority youth - where I do know some language but not local slang." 
"It kind of connects to the slowing down. Giving people another language other than words, in conflict words get tired and can be trigger points. It engages everything. Not just a floating head."

"I would hope more people would dare to use body language and it is much older than verbal language and is much faster and deeper. Getting this work to a larger stage."

From this workshop, it seems that embodied practices resonate with participants' own values and norms as mediators and critically, participants noted that it offers parties to conflict a new way to approach their differences, while allowing mediators the ability to better connect in a more neutral and psychically and physically engaged way.

\section{Conclusion}

Applied theatre, particularly participatory theatre and storytelling methods are useful techniques for mediation as they "create space for discussion and can allow for local ownership of the process of remembering, taking into account its religious, ethical, cultural, and psychosocial dimensions by addressing individual and collective needs" (Davaruth, 2005: 4). This allows parties to a conflict the space to develop greater critical thinking and analytic skill and the ability to understand multiple perspectives of said conflict, finding connection and themes that relate to all groups in their societies. That these processes incorporate more movement and visualization to guide individuals away from their standard script of grievances and demands toward a more thoughtful and nuanced understanding of a given conflict, does not seem to be lost on mediators, in part because this process entails more than just brokering a deal on paper.

The mediators in the ATC workshop seemed to understand intrinsically that words can very often get in the way of dialogue and as such, expressed interest in wanting to try incorporating more experiential and performative practices into their own work. In other words, "What would we know that we do not know now? Whose stories, memories, and struggles might become visible? What tensions might performance behaviours show that would not be recognized in texts and documents?" (Taylor, 2003: xviii). Addressing these questions, even when the words themselves fail, through an understanding of the body's place in conflict may help not only resolve conflicts and disputes under mediation but perhaps provide greater understanding and connection among parties to these conflicts that extend beyond the mediation process and into society as a whole. By supporting mediators to go beyond the conventional and explore the "constellation of acts" that are involved in making peace and settling disputes, we may have greater ability to ensure these acts sustain and endure to bring divided societies together in a tolerant, resilient, and rights-basedmanner. 


\section{References}

Benjamin, R. (2012) The Natural History of Negotiation and Mediation: The Evolution of Negotiative Behaviors, Rituals, and Approaches, Available at: Mediate.com/articles/NaturalHistory.

Bharucha, R. (2001) Between Truth and Reconciliation: Experiments in Theatre and Public Culture, Economic and Political Weekly 36 (39): 3763-3773.

Bush, R.B., Folger, J. (2004) The Promise of Mediation: Responding to Conflict Through Empowerment and Recognition, New York, Jossey-Bass.

Cohen, C.E. (2005) Creative Approaches to Reconciliation, 69-102, in M. Fitzduff and C.E. Stout (eds), The Psychology of Resolving Global Conflicts: From War to Peace; Vol. 3 Interventions, Westport, CT, Greenwood Publishing Group.

Cohen, C.E., Varea, R.G., Walker, P.O. (2011) Acting Together: Performance and the Creative Transformation of Conflict, Vol. 1, Resistance and Reconciliation in Regions of Violence, Oakland, CA, New Village Press.

Cohen-Cruz, J. (2005) Local Acts: Community Based Performance in the United States, New Brunswick, NJ, Rutgers University Press.

Davaruth, L. (2005) Notes of Pchum Ben, Working Paper, Recasting Reconciliation through Culture and the Arts, Coexistence International, Waltham/Boston, Brandeis University.

Maslach, C., Schaufeli, W.B., Leiter, M.P. (2001) Job Burnout, Annual Review of Psychology 52: 397-422.

Nathan, L. (2010) Towards a New Era in International Mediation, Policy Directions, London, Crisis States Research Centre, London School of Economics and Political Science.

Neelands, J. (2009) Acting Together: Ensemble as Democratic Process in Art and Life, Research in Drama Education: The Journal of Applied Theatre and Performance 14 (2): 173- 89.

New York Peace Institute (2013) Basic Mediation Training Participant Manual, New York. Available at: http: nypeace.org/wp.../2013//Volunteer-Handbook.

Nicholson, H. (2005) Applied Drama: The Gift of Theatre, New York, Palgrave Macmillan.

Research Center for Leadership Action (2008) Story Circle Method Practice Note, New York, Wagner School, New York University.

Rothschild, B. (2000) The Body Remembers: The Psychophysiology of Trauma and Trauma Treatment, New York, W.W. Norton.

Singhal, A. (2004) Empowering the Oppressed through Participatory Theatre, Investigación y Desarrollo 12 (1): 138-63.

Taylor, D. (2003) The Archive and the Repertoire: Performing Cultural Memory in the Americas, Durham, NC, Duke University Press.

United Nations Assistance Mission in Afghanistan (UNAMA) (2008), Tears into Energy: Communitybased Theatre and transitional Justice, unpublished report.

Ury, W. (1999) The Third Side: Why We Fight and How we Can Stop, New York, Penguin Books. 
Authors' Note: Some of the material contained here also appears in a different form in Nadia Siddiqui, Hadi Marifat, and Sari Kouvo, "Culture, Theatre and Justice: Examples from Afghanistan," in Olivera Simic and Peter D. Rush (eds.) The Arts of Transitional Justice:

Culture, Activism and Memory after Atrocity, Springer Series in Transitional Justice 6 (New York: Springer Science + Business Media, 2014: 113-34).

Nadia Siddiqui is the Director of Strategy for the Applied Theatre Collective and is particularly interested in experiential learning, innovative problem-solving, and the links between cultural practice and justice, topics on which she has written and presented. She has developed projects in Afghanistan and the Middle East and has also produced successful art/design events in New York City. Nadia is currently based in Erbil, Iraq developing research on social cohesion and civic trust in divided societies and the intersection of justice and development in strategies to cope with mass displacement. She holds an MSc. in Evidence-Based Social interventions from the University of Oxford.

Michelle O'Connor-Hill is the Executive Director of the Applied Theatre Collective (ATC) an organization dedicated to establishing creative space for dialogue through arts. Ms. O'Connor- Hill is also Adjunct Faculty at New York University's Centre for Global Affairs, teaching courses that explore creative approaches to difficult problems. ATC has lead workshops with educators, mediators, and social workers in Dohuk, Iraq; Bucharest, Romania, Eastern Tennessee, and on the border between the US and Mexico in McAllen, Texas.

Brisa Areli Muñoz is the Artistic Director of the Applied Theatre Collective. She obtained her Masters in Applied Theatre from The City University of New York and is currently pursuing a Master's of Science in Organizational Change Management at The New School. She currently serves as an Associate Program Director at CUNY Creative Arts Team, a theatre organization that creates participatory dramas on social and political issues in hopes of engaging people in critical discourse.

Lili Nikolova is the Director of Programs of the Applied Theatre Collective. She is also a Project Manager of the "Expanding Access to Justice for Prisoners and Detainees" project at Heartland Alliance International in Iraq. She obtained her Master Degree in Peacebuilding and Conflict Resolution from New York University and is a certified mediator, who has worked in the peacebuilding and human rights field in Iraq, USA, Sri Lanka and Timor-Leste. 